\title{
Deconstructing Canada's efforts to integrate artificial intelligence in medicine and medical education
}

\author{
Semsi Kocabas $^{1} \quad$ | Elif Bilgic ${ }^{1} \quad$ | Andrew Gorgy ${ }^{1}$ | Jason M. Harley ${ }^{1,2,3}$
}

${ }^{1}$ Department of Surgery, McGill University, Montreal, QC, Canada

${ }^{2}$ Institute for Health Sciences, McGill

University, Montreal, QC, Canada

${ }^{3}$ Research Institute of the McGill University Health Centre, Montreal, QC, Canada

\section{Correspondence}

Jason M. Harley

Email: jason.harley@mcgill.ca

\section{Publication Date}

June 2, 2021

\section{MJM 2021 (19) 29}

https://doi.org/10.26443/mjm.v19i1.871

\section{\$. McGill \\ Journal of Medicine}

www.mjmmed.com

\section{(i) (2)}

This work is licensed under a Creative Commons BY-NC-SA 4.0 International License.

\section{ABSTRACT}

Artificial intelligence (AI) has gained momentum in the last decade in various professional domains, but its usage remains scarce in the field of medicine. Available Al-enhanced devices are not integrated in a consistent fashion throughout Canadian health facilities, and current medical practitioners and students are not well prepared for Al's impact on their careers. Undergraduate medical students lack fundamental knowledge of $\mathrm{Al}$ in medicine, from its impact on patient care and its potential as an adjunct decision-making tool, to the general fundamentals of how Al-enhanced devices work. Currently, postgraduates don't have access to Al-enhanced devices; this could potentially limit their understanding of how these devices might affect their future clinical practice. Canadian medical universities can play a critical role in familiarizing students with these new devices. Incorporating new topics into the already heavily charged medical curricula may be challenging, but students could make use of extracurricular activities to learn the concept of $\mathrm{Al}$ and strengthen interdisciplinary collaboration. Educational institutions would also need to propose policies for the safe and ethical use of devices in classrooms or internships. However, they might require guidance to draft new policies targeting $\mathrm{Al}$ in medical education. Canadian medical associations could take the lead to draft Al policies in healthcare to guide the equal and safe implementation of $\mathrm{Al}$-enhanced devices across the Canadian medical community. Our paper will explore the work that has been done related to Al-specific policies in healthcare, focusing on Canada, and provide key points that could be used to organize future policies.

\section{KEYWORDS}

Medical education, Artificial intelligence, Canadian education, Policy analysis 


\section{1 | INTRODUCTION}

Artificial intelligence (Al) in healthcare refers to a spectrum of technologies that consist of an algorithm receiving data as input, processing it, and giving an output to assist in diagnosis, treatment, patient monitoring, and trainee education. Although $\mathrm{Al}$ is gaining popularity across diverse fields such as finance and aviation, it has not yet been widely adopted within healthcare systems internationally. Currently, the most popular implemented role Al holds in medicine is providing evidencebased personalized treatment regimens for patients by processing local and widely available data libraries (e.g. Gemini by GNS Healthcare, or DynaMed-Micromedex by IBM). The impact of fully integrating Al-enhanced devices into clinical routine, from triage and early diagnosis to comparative drug effectiveness and office operations, is hence unknown. Al-related discoveries are mostly kept within the research and development community, leaving healthcare professionals inadequately informed about new Al developments. (1) This could impede medical professionals from using $\mathrm{Al}$ with ease as increasingly more complex tools are introduced to the market. Thus, there is a rising need to educate healthcare professionals about these devices. Currently, undergraduate and postgraduate medical education do not provide students with the foundations to comprehend the challenges of emerging Al technologies. Therefore, it is important to incorporate Al-related courses in medical education.

In order to properly integrate Al-enhanced devices into the healthcare system and educational institutions, medical associations and universities need to devise Alspecific policies. Policies would help introduce the devices to a greater audience of trainees and achieve equity in their access and safe use (e.g., protecting patient data) in medical practice and in educational settings. In Canada, legislation to adopt Al into the healthcare system does not currently exist. However, in recent years, there has been an initial governmental collaborative effort to develop new policies on $\mathrm{Al}$ in medicine and medical education. Whether there has been significant progress on their redaction has yet to be doc- umented. In what follows, we discuss the position of the Canadian government and medical associations on the topic of $\mathrm{Al}$ in medicine, medical schools' efforts to integrate $\mathrm{Al}$ in coursework and medical research labs, Al policies related to medical education internationally, and finally, suggestions for Canadian policymakers. If there is sufficient guidance from Canadian medical associations, universities could build on it to put forward their own norms on implementing $\mathrm{Al}$ in medical education and healthcare facilities.

\section{I HOW ARE THE CANADIAN GOVERNMENT AND MEDICAL ASSOCIATIONS ADDRESSING AI POLICIES IN HEALTHCARE?}

Canada was the first country to adopt a strategy on Al in the 2017 Budget to initiate its appraisal. (2) Led by the Canadian Institute for Advanced Research (CIFAR), the Pan-Canadian Al Strategy's objective was to bring together academic and industrial talent for potential innovation. To ensure that the use of Al would be governed by clear values and laws, the National Research Council was quick to release an advisory statement and a white paper draft on the responsible and ethical use of $\mathrm{Al}$ in 2017. $(3,4)$ While it addresses critical issues such as ethics, privacy, and bias, it does not go in-depth for applications in healthcare. It is the Al4Health Task Force under CIFAR that undertook the responsibility to underline urgent actions the government should take with respect to the deployment of $\mathrm{Al}$ in healthcare. Their report from July 2020 lists recommendations under four broad key messages: 1) Establish the infrastructure to securely access datasets, 2) Support the growth and the procurement of $\mathrm{Al}$ in the healthcare system, 3) Advance digital health by coupling it to policies, investments and partnerships of private enterprises and public institutions, and 4) Encourage federal and provincial healthcare partners to commit to a joint effort to ensure policy development. (5)

Canada's medical and subspecialty associations are also aware of the need to discuss the future of Al. In 
2013, the Canada Health Infoway wrote a summary on the high volume of available unstructured health data and stated that health ministries should address data policies on privacy, security, intellectual property, and liability. (6) Al-enhanced devices use algorithms trained using these types of datasets that should be prepared such that the data does not permit patient identification, but contains enough information to improve the algorithm's results. Since health data is part of the development process of $\mathrm{Al}$-enhanced devices, these issues require their own sets of policies. Additionally, in 2014, the Canadian Medical Protective Association followed with a call for physicians to become familiar with the concept and utility of "big data". (7) Al is one of the analytical devices that can process, contextualize, and visualize big data to recognize patterns. Therefore, it would be critical to write policies on collecting high quality data in a standardized way, while being aware of patient privacy concerns.

The Canadian Medical Association (CMA), especially during the COVID-19 pandemic, has been concentrating its efforts on virtual care and electronic medical records, since $63 \%$ of Canadians stated that they would like to be able to virtually access their family doctor according to a February 2020 task force report. (8) The report did not mention the relevance of $\mathrm{Al}$ within the telemedicine sphere. The last time the CMA acknowledged Al directly was during their 2018 Health Summit. (9) However, they reiterated in the 2020 report the potential of big health data in precision medicine, and that Al will improve diagnostic accuracy when using a high volume of datasets. Likewise, the Royal College of Physicians and Surgeons of Canada's (RCPSC) AI task force published a report in February 2020, in which they defined the place Al holds in medicine and gauged the impact it will have on healthcare and affected staff. (1) The report complemented the summit primer the CMA used to explore the potential of virtual care, big health data, and technological developments. (10) The RCPSC acknowledged that current health professionals are overlooking Al development due to the lack of Alrelated content in the medical curriculum. The report found that about half of the surveyed fellows answered that they had limited familiarity with Al. Only $3.9 \%$ of the surveyed fellows rated themselves as experts in the field. Additionally, the Canadian Association of Radiologists released a white paper on their stance on $\mathrm{Al}$ in 2018, which listed recommendations for preparing radiologists for the impact of $\mathrm{Al}$ regarding its implementation, governance, clinical implication, and education. (11) Overall, the governing bodies of the medical community (CMA and RCPSC) have engaged with the topic of $\mathrm{Al}$ in medicine. Therefore, they are well placed to initiate a collaboration among themselves to combine their respective insights and suggest future directions for Al in medical education to prepare current and future physicians.

\section{3 | THE PRESENT STATE OF AI IN MEDICAL SCHOOLS AND UNI- VERSITIES}

\section{1 | What are the actions set in motion by Canadian universities to prepare medical professionals for the impact of $\mathrm{Al}$ in healthcare?}

Based on the Canadian Association of Radiologists report, there is a need to offer an unbiased Al education to current and future physicians. The RCPSC report confirms this need, as $85 \%$ of surveyed residents affirmed not receiving adequate knowledge regarding the future usage of $\mathrm{Al}$ in their practice. Students from University of Toronto's medical school have taken the initiative to focus on this gap as part of the Ontario Medical Students Association (OMSA). In 2019, the OMSA drafted a position paper with recommendations to prepare students for the impact of Al. (12) It sums up learning objectives to gain $\mathrm{Al}$ competencies, comprehend the ethical implications and bias of algorithms, and expand interprofessional collaborations with other fields (e.g., computer science). The revised version of the paper has been included as one of the resolutions adopted at the $2020 \mathrm{An}$ nual Grand Meeting of the Canadian Federation of Medical Students. (13) From their appendix table, only the faculties of medicine from the University of Toronto and 
the University of British Columbia have lectures dedicated to $\mathrm{Al}$, with the latter mentioning it in a few radiology lectures. Other curricular offerings include Al in health research groups or education centres, which are available at Dalhousie University, McGill University, Western University, the University of Saskatchewan, and the University of Alberta. Medical school programs could also use existing courses on $\mathrm{Al}$ in medicine as templates to build their own courses. There could be difficulty in modifying the already established core curricula, so the course could be offered as an elective. For example, the course on $\mathrm{Al}$ in Medicine offered by the McGill University Faculty of Medicine and Health Sciences Department of Experimental Surgery could serve as a course template for other programs and universities. (14) There is an urgency to integrate Al into medical education to help future professionals gain familiarity with $\mathrm{Al}$ and its potential applications in the healthcare system. The OMSA's paper has shown that 50\% of the 14 interviewed medical schools had no extra-curricular interest groups dedicated to Al. (13) Therefore, having consistency in available workshops and seminars throughout all the Canadian medical schools would at least increase the awareness of Al among students, which could be a good starting point before more robust additions to the curricula.

Some Canadian universities' stances on Al in healthcare can be inferred from their latest academic strategic plans. The University of Toronto, for example, has marked $\mathrm{Al}$ as one of its priorities in their "Groundbreaking Imagination" domain of focus. In 2020, they established a Centre for Al Research and Education in Medicine as a common hub for multidisciplinary collaborations. (15) The University of Alberta, through their Precision Health Initiative, has made recommendations for Al seminars, capstone projects, and training opportunities in the Faculty of Medicine and Dentistry. They have also established an Education and Engagement Task Force to develop educational strategies to involve their trainees. (16) Such efforts could provide students with the necessary conceptual knowledge to understand the place Al can hold in various medical subspecialties. This includes a brief history on $\mathrm{Al}$, the research and development progress of $\mathrm{Al}$ in different cases, the ethical issues behind optimizing $\mathrm{Al}$, the need for improvement, and how the accuracy of such devices can affect clinical outcomes. After the initial undergraduate education, residents could have the chance to familiarize themselves with using $\mathrm{Al}$-enhanced devices as a part of their decision-making process, through both simulated practical scenarios and during their clinical rotations. In the near future, several Canadian medical universities could be using $\mathrm{Al}$ in their simulation centers, although currently, it is only found among their research and development groups. For example, although still in the research phase, a project in the University of Alberta's Surgical Simulation Research Lab demonstrates the feasibility of obtaining data from residents during an augmented reality surgical procedure to feed into a learning algorithm to detect the moment of performance difficulty. (17)

These two instances - the implementation of Al conceptual knowledge and literacy in undergraduate medical education and the use of Al-enhanced devices in postgraduate programs - illustrate the need to develop educational Al policies in faculties, simulation labs, and educational research centers. While universities might find it hard to truly gauge the effect of $\mathrm{Al}$ in medicine, they can always turn to existing research institutes for direction. The Vector Institute, the Montreal Institute for Learning Algorithms (MILA), and the Alberta Machine Intelligence Institute (Amii), to name a few, are Al hubs that could help institutions navigate the multiple facets of $\mathrm{Al}$ and act as a link to CIFAR, which has already begun a nationwide Al policy labs initiative. (18) By evaluating the full effect of $\mathrm{Al}$ in medicine, universities can create policies to incorporate relevant conceptual and practical Al knowledge into medical school and residency curricula, respectively, focusing on the safe and ethical use of Al-enhanced devices with the provided data.

\subsection{How are Al policies in medical education integrated internationally?}

The American Medical Association (AMA) has taken the 
North American lead by passing its first Al policy in 2018 titled "Augmented Intelligence in Health Care". (19) It broadly sets the agenda, ensuring that $\mathrm{Al}$ initiatives be smoothly integrated and thoughtfully designed, minimizing disruption of patient-physician interaction. Additionally, in 2019, the AMA's Council of Medical Education adopted 10 additional policies to ensure $\mathrm{Al}$-specific advances were supported by medical education. (20) Their goal is to study the most effective ways to include Al in licensing standards, modify the curricula to include specialty-specific educational modules, ascertain the quality of $\mathrm{Al}$ instruction in medical education, and judge the disparities in institutional access to Al.

Internationally, there seems to be no other mention of adopting Al policies in medical education since curriculum modifications to align humans and machines in practice have only recently been sought in editorials and published reviews. (21-23) The Academy of Royal Medical Colleges in the United Kingdom acknowledges that clinicians' education will require changes in order for them to be involved in the development of new technologies as the main users. (24) As the graduate medical curricula advocates for student-personalized education, Al could also provide custom training by evaluating previous training sessions. (25) However, such changes would require collaboration between medical schools and medical associations to ensure an appropriate reform to the curricula.

\section{I HOW SHOULD CANADIAN STAKEHOLDERS MOVE FOR- WARD?}

On the national, provincial, and local levels, every stakeholder will need to collaborate closely to ensure the follow-through of recommendations and adoption of broad $\mathrm{Al}$ in practice and educational policies. The Al4Health Task Force could act as the main body and serve as a connection in the network of research institutes and universities, relaying and summarizing the latest information on the development of $\mathrm{Al}$ and its availability throughout the provinces. They already have the
Al Futures Policy Labs, which paves the way for discussion among policymakers from the public, private, academic, and not-for-profit sectors across Canada. (18) Medical associations could collect comments from clinicians who have had contact and experience with $\mathrm{Al}$ enhanced devices. This feedback could be forwarded to medical schools, resulting in relevant learning objectives and assessments. This also includes potentially modifying the CanMEDS framework of the RCPSC to include Al competencies in defined roles, such as digital literacy for scholars or transparent implementation of technologies as a leader. (26) Canadian universities, using feedback and newly-acquired knowledge from universityassociated research institutes, should review their curricula to encompass an overview of medical usage of $\mathrm{Al}$, societal issues, clinical impact, and training with Alenhanced simulation devices. The CMA and RCPSC could jointly draft tentative educational policies that universities could adapt to their needs. Based on the abovementioned reports and the AMA's policies, the following key points could be used to organize future broad educational policies into different sections:

A policy to fill the knowledge gap. Current practitioners and trainees should receive training modules to complement their clinical practice. Care should be taken to ensure that the material presented in the workshops or modules covers the basics of Al algorithms, available accessible $\mathrm{Al}$-enhanced devices, and the relevant usage instructions of each device.

A policy to practice data protection. Secure Canadian data banks should be created and have clear policies and procedures for collecting patients' informed consent. Data privacy and confidentiality should be a top priority. A policy in this case would ensure that the right information is shared with health professionals, with additional details pertinent to subspecialties, such as radiology, pathology, and surgery. Such a policy would also digitally secure patients' personal information.

A policy to guarantee the competence of medical students. Universities should offer extracurricular activities to promote collaboration between medical students, residents, healthcare providers, data scientists, 
and engineers to develop new devices and gain new perspectives. Students in medicine do not have to learn the mathematical development behind an algorithm, but they should learn how to describe their users' needs and the clinical applications of Al-enhanced devices developed by other researchers. Students should also learn about the relevance of $\mathrm{Al}$ and its evolution in each medical specialty. Additional courses, such as predictive imaging analysis for radiologists or robot-assisted surgery in surgical education, would also be advantageous for students, as would the use of simulation labs to carry out simulations and research involving Al. This policy would aim to provide undergraduate students with access to the conceptual knowledge of $\mathrm{Al}$ and interdisciplinary team collaborations, in addition to ensuring that postgraduate students have hands-on experience receiving input from $\mathrm{Al}$-enhanced devices during their residency.

\section{5 | CONCLUSION}

Although Al policies are still in their infancy, there is a strong foundation for future iterations among the reports of the Canadian health task forces and medical associations. They provide a baseline of recommendations that could serve to develop further policies on data management, digital literacy, and ethical issues brought by $\mathrm{Al}$ in medicine. The next step would be to appoint policymakers from Canadian medical associations, specifically the CMA and RCPSC, to introduce a clear first set of policies on the integration of $\mathrm{Al}$ in the healthcare system, and subsequently broad ones for $\mathrm{Al}$ in medical education. Canadian universities can draw on frameworks and guidelines from medical associations to guide their own policies and curricula. While some universities might not yet have access to Al-enhanced devices, they could include a course to introduce key concepts to undergraduate medical students that could include common use cases and ethical issues of $\mathrm{Al}$ in medicine. Policies would ensure that knowledge on $\mathrm{Al}$ is being taught to students ahead of the era of $\mathrm{Al}$ in medicine. Such a course design was successfully piloted at the University of Toronto in 2018 and included in the core curriculum in the 2019-2020 and 2020-2021 school years. (27) Postgraduate medical education could then integrate clinical usage of Al with real-life examples, in collaboration with university research centers and $\mathrm{Al}$ institutes. Doing so would support medical students in building competency to effectively use $\mathrm{Al}$ in their daily practices as future physicians.

\section{6 | ACKNOWLEDGEMENTS}

This research was supported by funding from the Social Sciences and Humanities Research Council of Canada (SSHRC: Grant ID: 611-2020-0157) awarded to J.M.H. as well as start-up funds from the Department of Surgery, Faculty of Medicine and Health Sciences, McGill University also awarded to J.M.H.

All authors have no relevant conflicts of interest or financial ties to disclose.

\section{REFERENCES}

1. The Royal College of Physicians and Surgeons of Canada: Artificial intelligence (Al) and emerging digital technologies [Internet]. 2020 Feb [cited 2020 Oct 25]. Available from: https://www.royalcollege.ca/rcsite/health-policy/initiatives/aitask-force-e

2. Canada first to adopt strategy for artificial intelligence | United Nations Educational, Scientific and Cultural Organization [Internet]. 2018 [cited 2020 Sep 23]. Available from: http://www.unesco.org/new/en/media-services/single-view/ news/canada_first_to_adopt_strategy_for_artificial_intelligence/

3. Canada National Research Council. Advisory statement on human ethics in artificial intelligence and big data research [Internet]. 2017 [updated 2019 Mar 26; cited 2020 Oct 1]. Available from: https://nrc.canada.ca/en/corporate/values-ethics/researchinvolving-human-participants/advisory-statement-human-ethicsartificial-intelligence-big-data-research-2017

4. Treasury Board of Canada. Responsible Al in the Government of Canada [Internet]. Digital Disruption White Paper Series. Version 2.0. Google Docs. 2018 April 10 [cited 2020 Oct 25]. Available from: https://docs.google.com/document/d/1SnqBZUXEUG4dVk909eSg5qvfbpNIRhzlefWPtBwbxY/

5. Building a Learning Health System for Canadians [Internet]. CIFAR. 2020 Aug [cited 2020 Nov 17]. Available from: https://www.cifar.ca/ai/pan-canadian-artificial-intelligencestrategy/building-a-learning-health-system-for-canadians 
6. Big Data Analytics in Health White Paper (Executive Summary) | Canada Health Infoway [Internet]. 2013 May 6 [cited 2020 Oct 2]. Available from: https://www.infowayinforoute.ca/en/component/edocman/resources/technicaldocuments/emerging-technology/1249-big-data-analytics-inhealth-white-paper-executive-summary

7. The impact of big data on healthcare and medical practice [Internet]. The Canadian Medical Protective Association. 2014 [cited 2020 Oct 2]. Available from: https:// www.cmpa-acpm.ca/static-assets/pdf/research-and-policy/publicpolicy/com_14_big_data_design-e.pdf

8. Virtual Care [Internet]. Canadian Medical Association. 2020 Feb [cited 2020 Nov 18]. Available from: https://www.cma.ca/virtualcare

9. 2018 Highlights - CMA Health Summit [Internet]. 2018 [cited 2020 Dec 11]. Available from: https://cmahealthsummit.ca/2018highlights/

10. The Canadian Medical Association. The future of technology in health and health care: a primer [Internet]. 2018 [cited 2020 Oct 25]. Available from: https://www.cma.ca/sites/default/files/pdf/ health-advocacy/activity/2018-08-15-future-technology-healthcare-e.pdf

11. Tang A, Tam R, Cadrin-Chênevert A, Guest W, Chong J, Barfett J, et al. Canadian Association of Radiologists White Paper on Artificial Intelligence in Radiology. Can Assoc Radiol J. 2018 May;69(2):120-35. https://doi.org/10.1016/j.carj.2018.02.002

12. Harish V, Bilimoria K, Mehta N, Morgado F, Aissiou A, Eaton $\mathrm{S}$, et al. Preparing Medical Students for the Impact of Artificial Intelligence on Healthcare [Internet]. Ontario Medical Students Association. Position Paper. 2019 [cited 2020 Sep 22]. Available from: https://omsa.ca/sites/default/files/policy_or_position_paper/115/ position_paper_preparing_medical_students_for_artificial _intelligence_2019_feb.pdf

13. Canadian Federation of Medical Students's 2020 Annual Grand Meeting [Internet]. 2020 Sep [cited 2020 Sep 22]. Available from: https://cfms.org/meetings/agm-2020-Iondon

14. McGill University, Faculty of Medicine. EXSU 500 Artificial Intelligence in Medicine ( 3 credits) [Internet]. eCalendar. 2018 [cited 2020 Nov 27]. Available from: https://www.mcgill.ca/study/20182019/courses/exsu-500

15. Academic Strategic Plan 2018-2023 [Internet]. Faculty of Medicine. 2018 [cited 2020 Oct 25]. Available from: https:// medicine.utoronto.ca/asp

16. Precision Health | Faculty of Medicine Dentistry [Internet]. 2020 Jan [cited 2020 Oct 25]. Available from: https:// www.ualberta.ca/medicine/research/innovation/precisionhealth/index.html

17. Building a Better Surgeon [Internet]. 2019 Sep [cited 2020 Nov 20]. Available from: https://www.ualberta.ca/ medicine/momentum/2019/momentum-stories-2019/2019/ september/building-a-better-surgeon.html
18. Al Futures Policy Labs [Internet]. CIFAR. 2019 May [cited 2020 Sep 23]. Available from: https://www.cifar.ca/ai/ai-society/aifutures-policy-labs

19. AMA passes first policy recommendations on augmented intelligence [Internet]. American Medical Association. 2018 Jun 14 [cited 2020 Oct 25]. Available from: https://www.amaassn.org/press-center/press-releases/ama-passes-first-policyrecommendations-augmented-intelligence

20. AMA: Take extra care when applying $\mathrm{Al}$ in medical education [Internet]. American Medical Association. 2019 Jun 12 [cited 2020 Oct 24]. Available from: https://www.ama-assn.org/practicemanagement/digital/ama-take-extra-care-when-applying-aimedical-education

21. Wartman SA, Combs CD. Medical Education Must Move From the Information Age to the Age of Artificial Intelligence. Acad Med. 2018;93(8):1107-9. https://doi.org/10.1097/ ACM.0000000000002044

22. Sapci A, Sapci H. Artificial Intelligence Education and Tools for Medical and Health Informatics Students: Systematic Review. JMIR Med Educ. 2020;6(1):e19285. https://doi.org/10.2196/19285

23. Masters K. Artificial intelligence in medical education. Med Teach. 2019;41(9):976-980. https://doi.org/10.1080/ 0142159X.2019.1595557

24. Academy of Medical Royal Colleges. Artificial Intelligence in Healthcare [Internet]. 2019 [cited 2020 Oct 1]. Available from: https://www.aomrc.org.uk/wp-content/uploads/ 2019/01/Artificial_intelligence_in_healthcare_0119.pdf

25. Bissonnette V, Mirchi N, Ledwos N, Alsidieri G, WinklerSchwartz A, Del Maestro RF. Artificial Intelligence Distinguishes Surgical Training Levels in a Virtual Reality Spinal Task. J Bone Joint Surg. 2019 Dec 4;101(23):e127. https://doi.org/10.2106/JBJS.18.01197

26. Rampton V, Mittelman M, Goldhahn J. Implications of artificial intelligence for medical education. Lancet Digit Health. 2020 Mar 1;2(3):e111-2. https://doi.org/10.1016/S2589-7500(20)30023-6 27. McCoy LG, Nagaraj S, Morgado F, Harish V, Das S, Celi LA. What do medical students actually need to know about artificial intelligence? Npj Digit Med. 2020 Jun 19;3(1):1-3. https://doi.org/10.1038/s41746-020-0294-7 